\title{
Influence of coral and algal exudates on microbially mediated reef metabolism
}

Benthic primary producers in tropical reef ecosystems can alter biogeochemical cycling and microbial processes in the surrounding seawater. In order to quantify these influences, we measured rates of photosynthesis, respiration, and dissolved organic carbon (DOC) exudate release by the dominant benthic primary producers (calcifying and non-calcifying macro-algae, turf-algae and corals) on reefs of Moorea French Polynesia. Subsequently, we examined planktonic and benthic microbial community response to these dissolved exudates by measuring bacterial growth rates and oxygen and DOC fluxes in dark and daylight incubation experiments. All benthic producers exuded significant quantities of DOC (roughly $10 \%$ of their daily fixed carbon) into the surrounding water over a diurnal cycle. However responses of the microbial communities were dependent upon the source of the exudates and whether the microbes were collected from benthic or planktonic environments. Without exudates present the planktonic and benthic microbial communities exhibited opposing influences on DO concentration (were net heterotrophic versus autotrophic, respectively). Coral exudates caused a shift towards a net autotrophic microbial metabolism by increasing the net production of oxygen by the benthic and decreasing the net consumption of oxygen by the planktonic microbial community. In contrast, algal exudates decreased the net production by the benthic and increased the net consumption of oxygen by the planktonic microbial community thereby resulting in a shift towards net heterotrophic community metabolism. When scaled up to the reef habitat, exudate-induced effects on microbial respiration did not outweigh the high oxygen production rates of benthic algae, such that reef areas dominated with benthic primary producers were always estimated to be net autotrophic. However, estimates of microbial consumption of DOC at the reef scale surpassed the DOC exudation rates suggesting net consumption of DOC at the reef-scale. In situ mesocosm experiments using custom-made benthic chambers placed over different types of benthic communities exhibited identical trends to those found in incubation experiments. Here we provide the first comprehensive dataset examining direct primary producer-induced, and indirect microbially mediated alterations of elemental cycling in both benthic and planktonic reef environments over diurnal cycles. Our results highlight the 
variability of the influence of different benthic primary producers on microbial metabolism in reef ecosystems and the potential implications for energy transfer to higher trophic levels during shifts from coral to algal dominance on reefs. 


\section{Influence of coral and algal exudates on microbially mediated reef metabolism}

Andreas F. Haas ${ }^{1,2^{*}}$, Craig E. Nelson ${ }^{3}$, Forest Rohwer ${ }^{1}$, Linda Wegley-Kelly ${ }^{1}$, Steven D. Quistad $^{1}$, Craig A. Carlson ${ }^{3,4}$, James J. Leichter ${ }^{2}$, Mark Hatay ${ }^{1}$ and Jennifer E. Smith ${ }^{2}$ ${ }^{1}$ Department of Biology, San Diego State University ${ }^{2}$ Scripps Institution of Oceanography, University of California San Diego ${ }^{3}$ Marine Science Institute, University of California Santa Barbara ${ }^{4}$ Department of Ecology, Evolution and Marine Biology, University of California Santa Barbara 


\section{Abstract}

Benthic primary producers in tropical reef ecosystems can alter biogeochemical cycling and microbial processes in the surrounding seawater. In order to quantify these influences, we measured rates of photosynthesis, respiration, and dissolved organic carbon (DOC) exudate release by the dominant benthic primary producers (calcifying and non-calcifying macro-algae, turf-algae and corals) on reefs of Moorea French Polynesia. Subsequently, we examined planktonic and benthic microbial community response to these dissolved exudates by measuring bacterial growth rates and oxygen and DOC fluxes in dark and daylight incubation experiments. All benthic producers exuded significant quantities of DOC (roughly $10 \%$ of their daily fixed carbon) into the surrounding water over a diurnal cycle. However responses of the microbial communities were dependent upon the source of the exudates and whether the microbes were collected from benthic or planktonic environments. Without exudates present the planktonic and benthic microbial communities exhibited opposing influences on DO concentration (were net heterotrophic versus autotrophic, respectively). Coral exudates caused a shift towards a net autotrophic microbial metabolism by increasing the net production of oxygen by the benthic and decreasing the net consumption of oxygen by the planktonic microbial community. In contrast, algal exudates decreased the net production by the benthic and increased the net consumption of oxygen by the planktonic microbial community thereby resulting in a shift towards net heterotrophic community metabolism. When scaled up to the reef habitat, exudate-induced effects on microbial respiration did not outweigh the high oxygen production rates of benthic algae, such that reef areas dominated with benthic primary producers were always estimated to be net autotrophic. However, estimates of microbial consumption of DOC at the reef scale surpassed the DOC exudation rates suggesting net consumption of DOC at the reef-scale. In situ mesocosm experiments using custom-made benthic chambers placed over different types of benthic communities exhibited identical trends to those found in incubation experiments. Here we provide the first comprehensive dataset examining direct primary producer-induced, and indirect microbially mediated alterations of elemental cycling in both benthic and planktonic reef environments over diurnal cycles. Our results highlight the variability of the influence of different benthic primary producers on microbial metabolism in reef ecosystems and the potential implications for energy transfer to higher trophic levels during shifts from coral to algal dominance on reefs. 


\section{Introduction}

Coral reefs, although generally located in oligotrophic environments, are one of the most biodiverse ecosystems on the planet, due largely to their high productivity and efficient nutrient recycling mechanisms (Done et al. 1996). In recent years coral reefs have suffered many impacts, from local anthropogenic influences such as pollution, fishing, and coastal development, to global climate change including warming and likely future acidification of the oceans (Hough-Guldberg et al. 2007). In many areas, these impacts have led to changes in community structure often resulting in a phase shift (McCook 1999), in which the benthic communities shift from dominance by corals to fleshy algae (McManus and Polsenberg 2004, Smith et al. submitted). These shifts in benthic community structure have dramatic implications for the overall trophic structure of tropical reefs as corals provide habitat and shelter for numerous taxa (Paine 1980; Alongi 1994). In addition, different benthic primary producers influence reef communities in multiple, distinct ways by regulating the availability of various inorganic and organic resources and altering the physical structure of the benthos (Done 1992; Wild et al 2011).

Organic material supplied to the ecosystem by benthic primary producers as exudates is thought to play a pivotal role in community-wide transitions on coral reefs (Jones et al 1997, Wild et al. 2004a). Exudates may serve different ecological functions depending on their origin. Coral exudates may keep valuable resources in oligotrophic reef systems by trapping particles from the water column, which are remineralized by the benthic microbial communities. In contrast, algae derived exudates have been shown to stimulate rapid growth of planktonic microbies (Haas et al 2011) and community shifts towards copiotrophic and potentially pathogenic microbial communities in the water column (Nelson et al. 2013). Despite an increasing focus on microbial cycling of carbon in recent years, little is still known about the variability in microbial uptake of dissolved organic matter (DOM) and the potential influence it may have on biogeochemical cycling.

Previous studies of tropical reef-associated primary producers have shown that all primary producers release a significant portion of their photosynthetically fixed carbon immediately into their environment (Crossland 1987, Ferrier-Pages et al. 1998, Wild et al 2010). It has further been established that fleshy macroalgae and especially small $(<2 \mathrm{~cm})$ filamentous algal turfs generally have noticeably higher DOC release rates than calcifying primary producers including hermatypic corals. These results are consistent over a wide range of reef systems, comprising the Red Sea (Haas et al. 2010a, Naumann et al. 2012), the Caribbean (Haas et al 2010b), and the Central Pacific (Haas et al. 2011). 
However, counter to expectations, Nelson et al. (2011) demonstrated that in a backreef system dominated by algae rather than corals, DOC concentrations were significantly lower than in the surrounding offshore waters. Other studies (Dinsdale et al. 2008) incorporating multiple islands in the central Pacific have shown similar patterns where fleshy algal abundance is inversely related to DOC concentrations in the water column. This surprising inverse correlation may be explained by a significantly more heterotrophic microbial metabolism following initially higher availability of algae derived bio-available DOC. A system wide decrease in DOC concentrations could then be the result of a) increases in the abundance of heterotrophic microbes (Dinsdale et al. 2008) and, b) a co-metabolism, which occurs when microbes are given an initial surplus of labile carbon, enabling this bacterial community to utilize refractory carbon sources (Carlson et al. 2002).

Recent research has shown that macroalgae derived exudates, enriched in the dissolved combined neutral sugar components Fucose and Galactose, facilitate significantly higher rates of bacterioplankton growth and concomitant DOC utilization than coral exudates or untreated seawater (Haas et al 2011, Nelson et al. 2013). Further, microbial communities growing in different exudates selectively remove different dissolved combined neutral sugar (DCNS) components, whereby the bacterial communities growing on algal exudates have significantly higher utilization rates of the sugar components which were enriched in the respective algal exudates. Analysis of microbial community composition identifies clear differentiation between the communities selected for by algae exudates and those growing on coral exudates or seawater controls. Macroalgae fostered rapid growth of less diverse communities and selected for copiotrophic bacterial populations with more opportunistic pathogens - so called super-heterotrophic communities (Nelson et al. 2013, Dinsdale and Rohwer 2010). In contrast coral exudates engendered a smaller shift in bacterioplankton community structure and maintained relatively high diversity.

The microbial landscape on tropical reefs, however, is not only restricted to the water column directly adjacent to the reef benthos $\left(\sim 10^{5}-10^{6} \mathrm{~cm}^{-3}\right.$ ) (Azam 1983, McDole et al. 2012). In addition to microbes associated with benthic macro-organisms $\left(>10^{7} \mathrm{~cm}^{-2}\right.$ surface area) (Rosenberg et al. 2007), those associated with calcareous reef sands $\left(\sim 10^{9} \mathrm{~cm}^{-3}\right)$ (Schöttner et al 2011, Hansen et al.,1987, Sørensen et al., 2007; Rusch et al., 2009) and the vast porous reef structures in the reef matrix (de Goeij et al 2008) may also play a significant role in biogeochemical cycling (Capone et al., 1992, Wild et al. 2005b, Werner et al. 2008, Scheffers 2004). Surface associated microbes may carry out multiple ecological functions, such as nitrogen fixation or inhibition of potential pathogens (Brown and Bythell 2005) for PeerJ reviewing PDF | (v2013:04:457:1:1:NEW 27 Jun 2013) 
their host organisms. The benthic microbial communities, living in the reef structure or reef sands, on the other hand have been recognized as important components for the reef community, as they are capable of rapidly reallocating nutrients in the otherwise oligotrophic tropical reef environments (Rasheed et al. 2004). They also may constitute an essential food source for protists and invertebrates, forming the base of benthic food webs (Alongi 1994). Next to remineralization and redistribution of nutrients, recent studies have emphasized the role of the benthic microbial communities as important primary producers in these ecosystems (Boucher et al. 1998, Clavier and Garrigue 1999, Heil et al. 2004, Werner et al. 2008).

Like the planktonic microbial communities, benthic microbes, although significantly different in community composition (Hewson and Fuhrman 2006), are also known to be affected by primary producer derived exudates (Sjöling et al 2005, Wild et al. 2004b). However, their responses to these different types of organic matter have rarely been investigated (Wild et al. 2005b) and only one pilot study addressed these questions in the context of changing reef environments (Wild et al. 2009).Additionally, production, respiration and the contribution to the nutrient pool have been assessed independently for all of the above described groups, but their relative contribution to collective reef metabolism and their effects on each other have not been investigated on a community scale. Although there have been previous attempts to quantify primary production budgets in coral reefs (e.g. Odum 1968, Gordon 1971, Sournia 1976, Hatcher 1990) they did not account for how microbial metabolism associated with different reef organisms may influence these processes at a landscape scale (Hoegh-Guldberg et al. 2007, Hughes et al. 2007).

The goal of the present study was to quantify biochemical processes and metabolic rates of both benthic and planktonic microbial communities across different benthic assemblages over diurnal cycles. To verify the findings of our controlled incubation experiments we simultaneously conducted a series of in situ measurements, using collapsible benthic isolation tents (cBITs), which allow for continuous monitoring of enclosed portions of the reef benthos. These data present the first comprehensive assessment of how benthic primary producers influence surrounding seawater chemistry directly through metabolic processes and indirectly via changing the microbial landscape and metabolism in this ecosystem. Our study thus provides a system-wide overview of potential biochemical alterations facilitated by different primary producer communities on coral reefs.

\section{Material and Methods}

\section{Study Site}

PeerJ reviewing PDF | (v2013:04:457:1:1:NEW 27 Jun 2013) 
This study was conducted at the Richard B. Gump South Pacific Research Station located on the north shore of the island of Mo'orea, French Polynesia (17.48 S 149.84 W) from 1 to 22 September 2011. The high volcanic island of Mo'orea is encircled by a barrier reef approximately $1 \mathrm{~km}$ offshore, thereby creating a semi-enclosed backreef system. The reef ecosystem consists of an outer reef slope and a lagoon system comprising a backreef platform with average water depths of $3 \mathrm{~m}$, and a fringing reef bordering the island (Hench et al. 2008, Nelson et al 2011). The benthic community on the backreef platform, our main area of investigation, is composed of approximately $68.6 \pm 4.9 \%$ turf- and fleshy macroalgae, $22.7 \pm$ 4.4\% hermatypic coral and $8.1 \pm 2.0 \%$ sand (http://mcr.lternet.edu/data). Average daytime (06:00 to 18:00 h) PAR availability in the backreef study area during the entire study period was $\sim 580 \mu \mathrm{mol}$ quanta $\mathrm{m}^{-2} \mathrm{~s}^{-1}$ as measured in LUX in a 5 min resolution with $\mathrm{HOBO}^{\circledR}$ Pendant UA-002-64 light and temperature loggers at the water depth were organisms were collected $(2.0-2.5 \mathrm{~m})$. Lux were converted to $\mu \mathrm{mol}$ quanta $\mathrm{m}^{-2} \mathrm{~s}^{-1}$ PAR according to the approximation established by Valiela (1984): $1 \mathrm{mmol}$ quanta $\mathrm{m}^{-2} \mathrm{~s}^{-1} 400-700 \mathrm{~nm}=51.2$ LUX). Average backreef in situ water temperature at this depth was $26.8 \pm 0.6{ }^{\circ} \mathrm{C}$ with diurnal fluctuations of $2.4 \pm 0.4{ }^{\circ} \mathrm{C}$. These values were later used as reference to ensure natural light and temperature conditions during incubation experiments.

\section{Sample Collection}

Samples from four different species of benthic primary producers, each representing one of a major functional group in this backreef system, were collected using SCUBA. The investigated species comprised 1) a hermatypic coral, Pocillopora damicornis, 2) a crustaceous coralline red alga (CCA) Hydrolithon reinboldii, 3) a common fleshy macroalga in the backreef system, Dictyota ceylanica, and 4) a typical mixed consortium of turf algae. All specimens were collected from the backreef platform approximately $500-1000 \mathrm{~m}$ east of Paopao Bay (Cook's Bay) from water depths of $2.0-2.5 \mathrm{~m}$ and transferred in coolers to cultivation tanks within 1 hour using watertight zippered polyethylene bags. Specimens were collected in replicates of at least 20. Dictyota specimens and CCA, growing as rhodoliths, were collected as whole individuals. For turfing algae pieces of reef structure at least $95 \%$ covered by the algae were collected. Fragments of Pocillopora colonies were collected using pliers, with each fragment from a different colony. Pocillopora fragments were then fixed onto ceramic tiles using small amounts of coral cement (Instant Ocean, Holdfast ${ }^{\circledR}$ Epoxy Stick) in such a way that only living coral tissue was exposed to the incubation waters. All samples were collected 5 days prior to the respective incubation experiments and incubated in 
common flow-through ambient water tanks to allow for healing of potential tissue lesions. Algal overgrowth on the ceramic tiles and glue junction was removed regularly and all specimens were carefully checked for potential infestation of epibionts or endolithic boring organisms to avoid potential confounding effects on experimental results. Samples of all primary producers were chosen in a way that they had comparable surface areas with an average of $87.3 \pm 8.8 \mathrm{~cm}^{2}$.

\section{Primary Producer Incubations}

DOC release. Each benthic specimen was incubated in an individual beaker following Haas et al. (2011) with minor modifications as follows. Primary producer incubations were conducted over a $24 \mathrm{~h}$ cycle, to assess variations in daytime and night production rates. At dusk (1900 h) each specimen was placed into a randomized beaker containing $920 \mathrm{ml}$ freshly collected filter sterilized backreef seawater (sterilized by passage through pre-flushed $142 \mathrm{~mm}$ polyethersulfone filters; $0.2 \mu \mathrm{m}$ pore size). To measure initial DOC concentration, water was sampled from each beaker with an acid-washed HDPE syringe $(60 \mathrm{ml})$ and filtered through a GF/F filter (Whatman; $0.7 \mu \mathrm{m}$ nominal pore size) into precombusted glass storage vials with acid-washed Teflon septa. Parallel seawater controls were identical with no organism added. Primary producers were incubated overnight $12 \mathrm{~h}$ and DOC samples were again collected at $0700 \mathrm{~h}$ of the following day. Primary producers were then incubated for another $12 \mathrm{~h}$ in the remaining $800 \mathrm{ml}$ seawater. Final DOC samples were taken at around 1900h. Specimens were then removed from the beakers using acid-washed forceps and the remaining incubation water was processed for the different exudate incubations (see below). Surface area and volume of all specimens (DOC and $\mathrm{DO} / \mathrm{pH}$ incubations) were determined using the method described in detail by Haas et al (2011). Specimen volume was always $<3 \%$ of incubation waters.

Effects of primary producer physiology on DO. Parallel to the DOC release incubations, assessments of primary producer physiology on DO values of the surrounding water column were conducted. These incubations were set up simultaneously with and identical to the above described DOC incubation with the only difference being that beakers were sealed airtight with a low-density polyethylene film (Saran ${ }^{\mathrm{TM}}$ ) over the course of the experiment. The two parallel experiments allowed for reliable measurements of DOC release and algal physiology without the potential for contamination of DOC measurements across beakers (Haas et al 2011). Initial DO readings were obtained from each beaker using a HACH LANGE HQ40 multiparameter instrument (DO: precision $0.01 \mathrm{mg} \mathrm{l}^{-1}$, accuracy $\pm 0.05 \%$ ). DO 
readings were obtained in parallel to DOC sampling (1900 h, $0700 \mathrm{~h}, 1900 \mathrm{~h}$ ) following the protocol described by Haas et al. (2011).

\section{Exudate Incubations}

Microbial abundance and DOC fluxes. To resolve diel effects of different primary producer exudates on the ambient backreef microbial community and water chemistry, $48 \mathrm{~h}$ benthic and planktonic dilution culture incubations were conducted under natural light and in the dark. The remaining seawater from each replicate primary producer incubation beaker was filter-sterilized through a pre-flushed (1 L low-organic deionized water; Barnstead Nanopure) $0.2 \mu \mathrm{m}$ polyethersulfone filter (Pall SUPOR-200) and then inoculated with a) freshly collected unfiltered backreef seawater (100 mL incubation water : $40 \mathrm{~mL}$ inoculum) and b) with freshly collected sand (15 ml sand : $125 \mathrm{ml}$ incubation water) to add a compositionally-representative ambient planktonic or benthic microbial community to the sample exudate media, respectively. Of the four identical replicates generated in this way for each specimen one incubation vessel was then kept in the dark and a congruent sample under natural daylight conditions, both at in situ temperature over a time period of $48 \mathrm{~h}$. Samples for TOC (DOC plus bacterial carbon) analysis and bacterial cell abundance were taken immediately after combining the exudates with the respective microbial inoculum and again at the end of the experiment. Bacterioplankton abundance was converted to carbon units assuming $20 \mathrm{fg} \mathrm{C}$ cell $^{-1}$ (Lee and Fuhrman 1987) and total DOC concentrations in the exudate incubation cultures was calculated by subtracting bacterial carbon from the measured TOC. All organic carbon samples $(30 \mathrm{ml})$ were collected in precombusted glass vials and immediately stored at - $20{ }^{\circ} \mathrm{C}$ for up to four months until analysis via high temperature catalytic oxidation according to Carlson et al. (2010). Additional samples for bacterial cell abundances (1-2 mL each) in the incubations were collected every $12 \mathrm{~h}$ over the $48 \mathrm{~h}$ incubation period. Bacterial abundance samples were immediately fixed in $0.5 \%$ paraformaldehyde and flash frozen at -80 ${ }^{\circ} \mathrm{C}$. Bacterial samples were stored for up to 2 months, and counted after $1 \mathrm{X}$ SYBR Green I (Invitrogen) staining via flow cytometry according to Nelson et al. (2011). A parallel incubation with the remaining two congruent samples for each specimen was performed to determine DO fluxes. The remaining inoculated sub-samples were transferred to ground-glass stoppered bottles (Wheaton BOD) and initial oxygen concentration of each sub-sample was determined as described above. Samples were kept airtight under natural light conditions or in the dark at in situ temperature $\left(26.6 \pm 0.5^{\circ} \mathrm{C}\right)$ alongside DOC/microbial incubations. After 48 $\mathrm{h}$ DO values were measured again to assess microbially mediated oxygen fluxes. 


\section{In Situ Benthic Isolation Tent Deployment}

Collapsible benthic isolation tents (cBITs) were used to assess effects of specific benthic communities in situ. The triangular pyramids, which were developed and built at the Smith and Rohwer laboratories, primarily consist of three transparent polycarbonate side panels joined by flexible polyvinyl chloride strips held erect by aluminum tubes which are connected by stainless steel cables. Tents were fixed to the ground with stainless steel pegs, with broad (25 cm) PVC flaps attached to the base of the tents to prevent water exchange, which were held flush to the sandy bottom with a $0.5-\mathrm{cm}$ gauge stainless steel anchor chain. Tents enclosed a volume of approximately $0.12 \mathrm{~m}^{3}$, and covered approximately $0.43 \mathrm{~m}^{2}$ of the reef surface. All tents were equipped with autonomous recording data loggers (Manta 2, Eureka environmental engineering) that monitored temperature (precision $0.01{ }^{\circ} \mathrm{C}$ ), DO (precision $0.01 \mathrm{mg} \mathrm{l}^{-1}$, accuracy $\pm 1 \%$, automatic temperature and pressure compensated and salinity corrected), and conductivity (accuracy $\pm 1 \%$, automatic temperature compensated) every 5 min over a minimum duration of 2 diurnal cycles (48 h). Further, tents were equipped with a circulation pump with tubing that recirculated water within the tents prior to sampling and, connected to a Niskin sampling bottle, served also as sampling port (Fig 1). Samples for DO, DOC, and bacterial abundance were collected every $24 \mathrm{~h}$ and processed as describe above. Five cBITs were set up simultaneously over 3 deployment periods $(n=15)$. Tents were mounted over selected benthic communities, comprising coral dominated, algae dominated, and sand dominated areas. Locations were chosen such that on each deployment period at least one representative of each of the respective benthic communities was included. After each deployment the benthic community enclosed by the cBITs was photographed for later determination benthic community composition. Photographs were processed using the digital image software Image $\mathrm{J}$, allowing determination of area occupied by the respective target organisms vs. the total projected area enclosed in each cBIT (Fig 1).

\section{Data Processing and Derived Variables}

In all incubation experiments, rates of change in DOC and DO concentrations and, where applicable, bacterial abundances were calculated by dividing the difference between start and end concentrations by the incubation duration (12 h for primary producer incubations, $48 \mathrm{~h}$ for exudate incubations). The proportional release of photosynthates in primary producer incubations was calculated as the ratio of DOC:DO fluxes. Daylight rates of change in exudate incubations were calculated by subtracting the rate of change in analytes in the $48 \mathrm{~h}$ 
dark incubation experiments from the rate of change in analytes in $48 \mathrm{~h}$ incubations subjected to ambient day-night conditions (i.e. light $=$ net - dark).

For incubations containing organisms or sand, rates of change in the assessed parameters were normalized per unit surface area of benthic material by dividing these rates by the surface area of the respective benthic organism or sand incubated in the starting replicate beaker (see Haas et al. 2011 for surface area determination). In the case of the sand incubations, the rates of planktonic change were subtracted to account for water column effects. For all following microbial incubations, concentration independency was assumed, supported by the lack of correlation between rates of change in microbial oxygen consumption and DOC starting concentrations (least squares - Model I - regression of oxygen fluxes on DOC starting concentrations: Benthic, $\mathrm{R}^{2}=0.000152 ; \mathrm{P}=0.9451$; Planktonic, $\mathrm{R}^{2}=$ 0.018995; $\mathrm{P}=0.3841)$.

To estimate how different benthic assemblages influence DOC and DO availability and microbial activity, rates of change were extrapolated to the backreef community of our study site. To apply proportional impacts of the collective benthic and planktonic microbial community on the reef water column we assumed an average of $3 \mathrm{~m}$ water column depth containing the planktonic microbial community above a $7 \mathrm{~mm}$ thick layer of permeable calcareous reef sands containing the benthic microbial community. Sand permeability depth was calculated using a custom porewater sampler to 1) isolate a $45 \mathrm{~cm}$ diameter patch of sand, 2) withdraw sequential $2 \mathrm{~L}$ volumes in which we 3 ) measure DO relative to overlying water; DO concentrations became hypoxic after $4 \mathrm{~L}$ volume giving a permeability depth estimate of roughly $7 \mathrm{~mm}$. This depth of exchangeable sand volume was replicated in the bottle experiments $(15 \mathrm{ml}$ sand across the $50 \mathrm{~mm}$ diameter glass bottle gives roughly $7 \mathrm{~mm}$ sand depth)

To assess rates of DOC concentration changes facilitated by the community enclosed in the respective cBITs, the difference between the concentrations in DOC samples collected at 0 and $24 \mathrm{hrs}$, were divided by the time between each the two sampling events (24 hrs). To calculate change in DO, sensor readings from deployment day 1 were subtracted from values measured at the exact same time point on deployment day 2. Hourly rates were then calculated by dividing the mean change from each measuring point from day one to day two by 24 (See Fig S1).

Statistics were performed using SAS within the software package JMP (v10; SAS Institute 1989-2011). All statistical tests were conducted on log-transformed data to meet assumptions of normality. We tested whether derived rates differed from control treatments PeerJ reviewing PDF | (v2013:04:457:1:1:NEW 27 Jun 2013) 
using analysis of variance (ANOVA) followed by Dunnett's post hoc test with $\alpha=0.05$. To test whether rates differed among the treatments we used Tukey's post hoc tests with $\alpha=0.05$. All rates are given in mean \pm standard error (SE) where applicable.

\section{Results}

\section{Exudate release rates and photosynthesis of benthic producers}

Mean rates of oxygen production during daylight by primary producers ranged from $24.5 \pm$ $0.9 \mu \mathrm{mol} \mathrm{L} \mathrm{L}^{-1} \mathrm{~h}^{-1}$ (Pocillopora) to $35.1 \pm 2.5 \mu \mathrm{mol} \mathrm{L}^{-1} \mathrm{~h}^{-1}$ (Dictyota). Nighttime oxygen consumption ranged from $5.7 \pm 0.6 \mu \mathrm{mol} \mathrm{L}^{-1} \mathrm{~h}^{-1}$ (CCA) to $7.0 \pm 0.7 \mu \mathrm{mol} \mathrm{L}^{-1} \mathrm{~h}^{-1}$ (turf). Rates of DOC release ranged from $0.9 \pm 0.3 \mu \mathrm{mol} \mathrm{L}{ }^{-1} \mathrm{~h}^{-1}$ (Pocillopora) to $5.5 \pm 1.8 \mu \mathrm{mol} \mathrm{L} \mathrm{L}^{-1} \mathrm{~h}^{-1}$

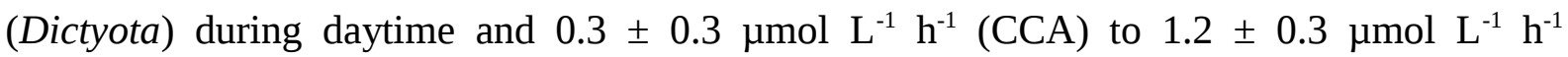
(Dictyota) during night. Seawater control fluxes during both daylight and nighttime were significantly smaller for DO $\left(-1.08\right.$ and $-0.57 \mu \mathrm{mol} \mathrm{L}^{-1} \mathrm{~h}^{-1}$; Dunnett's $\left.\mathrm{p}<0.001\right)$ and were on average smaller for DOC (0.29 and $\left.-0.28 \mu \mathrm{mol} \mathrm{L}^{-1} \mathrm{~h}^{-1}\right)$. Due to the small sample size, resulting from a loss of seawater control DOC samples, the latter was not statistically significant. All raw values of DO and DOC fluxes, facilitated by the primary producers are shown in Fig S2 and S3. When using oxygen production as a proxy for photosynthesis (Haas et al. 2011), the investigated primary producers released a mean of $12.6 \pm 2.5 \%$ of their photosynthetically fixed carbon as DOC in the surrounding reef waters. On average, the fleshy macroalga Dictyota released the highest proportion $(21.6 \pm 3.4 \%)$ of the assimilated carbon followed by turf algae (9.6 $\pm 4.2 \%)$, CCA (9.4 $\pm 3.4 \%)$, and Pocillopora $(7.2 \pm 4.2 \%)$.

In order to compare between effects facilitated by the different taxa, DO and DOC fluxes were corrected by normalizing the resulting values to the surface area of the respective organism. During daylight, oxygen production rates of primary producers significantly differed (ANOVA, $\mathrm{F}_{4,20}=27.9700, \mathrm{p}<0.0001$ ). Algae incubations showed significantly higher oxygen production rates than the seawater controls, whereby turf algae had the highest oxygen release rates per surface area of all incubated organisms (Tukey p < 0.05) (Fig 2.A). During dark incubations the primary producers exhibited significant differences in oxygen consumption rates (ANOVA, $\mathrm{F}_{4,20}=20.7842, \mathrm{p}<0.0001$ ). Congruent to daytime release rates, nighttime consumption was highest for turf, followed by Dictyota, CCA, and Pocillopora.

There were also significant differences in daytime DOC release rates between treatments (ANOVA, $\mathrm{F}_{4,7}=4.8069, \mathrm{p}<0.0350$ ). The noncalcifying alga Dictyota showed highest release rates followed by turf, CCA, and Pocillopora (Fig 2.A). There was no statistically significant difference in DOC release rates detectable between the primary PeerJ reviewing PDF | (v2013:04:457:1:1:NEW 27 Jun 2013) 
producers during dark incubations. However, similar to the daylight period, non-calcifying algae released on average higher amounts than the calcifying primary producers.

Over a whole diurnal cycle, net metabolic oxygen fluxes were significantly different between treatments (ANOVA, $\mathrm{F}_{4,20}=27.0087, \mathrm{p}<0.0001$ ). Turf algae had the highest rates of net oxygen production $\left(20.9 \pm 1.7 \mu \mathrm{mol} \mathrm{dm} \mathrm{dm}^{-2} \mathrm{~h}^{-1}\right)$ and Dictyota $\left(14.9 \pm 1.7 \mu \mathrm{mol} \mathrm{dm}{ }^{-2} \mathrm{~h}^{-1}\right)$

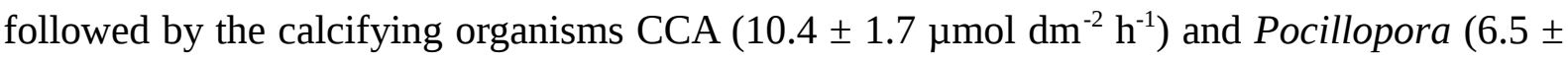
$2.2 \mu \mathrm{mol} \mathrm{dm} \mathrm{d}^{-2} \mathrm{~h}^{-1}$ ) had significantly lower rates of production (indicated in Fig 3.A). Similar differences were also detectable for net DOC release rates (ANOVA, $F_{4,6}=16.6025, p=$ 0.0021) whereby the fleshy alga Dictyota $\left(3.02 \pm 0.24 \mu \mathrm{mol} \mathrm{dm} \mathrm{d}^{-2} \mathrm{~h}^{-1}\right)$ and turf $(1.79 \pm 0.30$

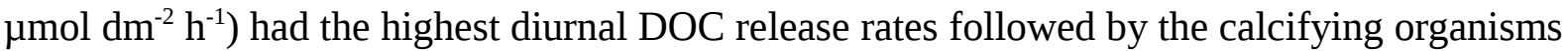
CCA $\left(0.95 \pm 0.25 \mu \mathrm{mol} \mathrm{dm}{ }^{-2} \mathrm{~h}^{-1}\right)$ and Pocillopora $\left(0.55 \pm 0.30 \mu \mathrm{mol} \mathrm{dm}^{-2} \mathrm{~h}^{-1}\right)$.

\section{Microbial Response}

Bacterial growth on organic matter released by benthic producers. There were significant differences in microbial growth rates in both the benthic and pelagic communities depending on the source of the exudates (Fig 4.A) and the type of incubation (light vs. dark). Although the rate of bacterioplankton growth in the $48 \mathrm{~h}$ dark incubations was not significantly different between the exudate treatments (ANOVA $\mathrm{F}_{4,19}=1.2482, \mathrm{p}>0.05$ ), there were noticeable differences under daylight conditions (ANOVA $\mathrm{F}_{4,18}=5.9043, \mathrm{p}=0.0032$ ). Exudates from turf algae resulted in the largest increase in bacterioplankton growth followed by CCA and Dictyota (Fig 4.C). Coral exudates caused an average decrease in microbial cells during daylight hours. These patterns, where turf algal exudates increased and coral exudates decreased pelagic microbial abundance, were also detectable over the whole diurnal cycle $\left(\right.$ ANOVA $\left._{4,18}=4.6153, \mathrm{p}=0.0090\right)$, (Fig 4.B).

While the benthic microbial communities responded differently to the exudate

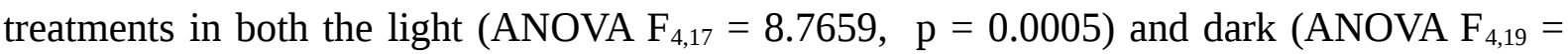
$7.2631 \mathrm{p}=0.0010$ ), the response was opposite that of planktonic microbial community (Fig 4.D). Under both light and dark conditions, turf algal exudates decreased bacterial cell growth, while coral exudates caused the highest growth rate for the microbial community living within the reef sands (Fig 4.D). Accordingly, these patterns were also detectable when both rates of daylight and dark benthic microbial growth were combined to calculate benthic microbial growth rates over a full diurnal cycle (ANOVA $F_{4,18}=16.7236 \mathrm{p}<0.0001$ ).

Planktonic microbially mediated effects. Planktonic dilution cultures, in which different exudates were added to ambient bacterioplankton communities, showed significant PeerJ reviewing PDF | (v2013:04:457:1:1:NEW 27 Jun 2013) 
differences in DO fluxes between the treatments both during daylight (ANOVA, $\mathrm{F}_{4,19}=$ 4.2349, $\mathrm{p}=0.0128$ ) and during dark (ANOVA, $\mathrm{F}_{4,20}=3.4412, \mathrm{p}=0.0270$ ) conditions. Exudates from the fleshy alga Dictyota and from turf algae resulted in the highest planktonic oxygen consumption rates both during dark and daylight conditions (Fig 2.B). While all of treatments containing algal exudates and the seawater controls exhibited decreases in DO concentrations during the day, incubations containing DOM derived from the coral Pocillopora displayed an average increase in DO (Fig 2.B).

Significant differences were also detectable in daytime planktonic TOC consumption rates $\left(\mathrm{ANOVA}, \mathrm{F}_{4,13}=4.6474, \mathrm{p}=0.0150\right.$ ), where microbial communities growing on exudates derived from Dictyota and turf showed highest carbon draw down rates. As with DO fluxes, incubations with coral exudates were the only treatments that resulted in increases of TOC concentrations during daylight incubations (Fig 2.B). Even though there were no statistical significant differences in TOC changes of planktonic microbial dilution cultures between the treatments during dark incubations, In general there was a trend whereby treatments containing algal exudates showed higher $\mathrm{C}$ draw down rates than treatments containing coral exudates or seawater controls suggesting enhanced mineralization processes, data also supported by the oxygen concentration measurements (Fig 2.B). Over a whole diurnal cycle the planktonic microbial community had net consumption of DO and DOC (Fig 3.B), with the exception of coral exudate incubations, which yielded net increases in DOC. Exudates of fleshy algae, and especially turf algae, resulted in significantly higher DO and DOC consumption rates than exudates derived from calcifying organisms (ANOVA, $\mathrm{F}_{4,20}=$ 4.3867, $\mathrm{p}=0.0104$ and ANOVA, $\mathrm{F}_{4,13}=4.9089, \mathrm{p}=0.0124$, respectively).

Benthic microbially mediated effects. Benthic incubations, where primary producer exudates were amended to ambient microbenthos communities, showed significant differences in DO release rates among treatments during daylight incubations (ANOVA, $\mathrm{F}_{4,19}$ $=9.5684, \quad \mathrm{p}=0.0002$ ). Relative to control incubations, turf algae exudates resulted in significantly lower benthic microbial oxygen production, while the microbial community growing in coral exudate treatments showed a greater photosynthetic oxygen production rate (Fig 2.C).

Significant differences in DO consumption rates were seen between the treatments during dark incubations (ANOVA, $\mathrm{F}_{4,19}=5.2539, \mathrm{p}=0.0051$ ) (Fig 2.C), with the highest oxygen consumption rates for incubations containing exudates from the fleshy alga Dictyota. Algal exudate incubations showed generally lower TOC release rates during daylight hours than the benthic microbial communities growing on coral exudates or seawater controls. PeerJ reviewing PDF | (v2013:04:457:1:1:NEW 27 Jun 2013) 
However, there was no significant difference in benthic microbe mediated TOC fluxes between the different treatments (Fig 2.C). However, algal exudate incubations showed generally lower TOC release rates during daylight hours than the benthic microbial communities growing on coral exudates or seawater controls.

Oxygen production rates of the microphytobenthos during the day living in the calcareous reef sands were always higher than the consumption rates during the night resulting in a net autotrophic metabolism over a whole diurnal cycle in all treatments (Fig 3.C). There were however significant differences between the treatments in net oxygen fluxes (ANOVA, $\mathrm{F}_{4,19}=13.6474, \mathrm{p}<0.0001$ ); turf algae exudates significantly decreased the productivity of the benthic microbial community, while coral exudates significantly increased microbial productivity. Exudates derived from macroalgae and calcifying algae had no significant effect on oxygen production rates of the microbenthic communities growing on sand (Tukey $\mathrm{p}>0.05$ ). All treatments showed TOC release of the benthic microbial community over a full diurnal cycle, though there were no statistically significant differences detectable between among the treatments (Fig 3.C).

Combined microbial effects. When extrapolated to a landscape scale within the lagoonon Moorea's backreef, the combined benthic and planktonic microbial metabolism in the seawater controls was net autotrophic during the daylight hours and heterotrophic during the night. These rates were roughly equal, thus over a diurnal cycle the combined microbial community metabolism (planktonic net heterotrophic and benthic net autotrophic) was balanced with neither DO nor TOC concentrations changing noticeably over 24 h (Fig 3.D). The addition of exudates had significant effects on the net microbial community metabolism for DO (ANOVA, $F_{4,19}=5.7686, p<0.0033$ ) and TOC (ANOVA, $F_{4,8}=7.7374, p<0.0074$ ) fluxes. Exudates derived from non-calcifying algae, especially turf, significantly increased oxygen (Dunnett's p < 0.0299) and DOC (Dunnett's p < 0.0467) consumption rates as a whole with an increase in planktonic microbial consumption and a decrease in benthic microbial production (Fig 3.D, Fig 5). In contrast, the combined microbial community metabolism resulted in increased net oxygen production in the presence of coral exudates, facilitating increases in DO and TOC concentrations of the surrounding water column. The shift towards an increasingly autotrophic microbial community in coral exudate incubations was due to reduced consumption rates by the planktonic microbial community and increases in the productivity of the benthic microbial community (Figs 3.B, 3.C, and 3.D).

\section{Community wide (microbial + macrobial) effects}

PeerJ reviewing PDF | (v2013:04:457:1:1:NEW 27 Jun 2013) 
Comparison of the extent of DOC and DO change facilitated by primary producer exudates and subsequent microbial metabolism showed that the high oxygen production rates of primary producers exceeded consumption by the combined planktonic and benthic microbial communities (Fig 3.E), maintaining overall net autotrophy in the system. The initially higher oxygen production by non calcifying algae (turf and Dictyota) compared to calcifying organisms (Pocillopora and Hydrolithon) was compensated by an exudate-mediated shift towards a more heterotrophic ambient microbial community, resulting in consistent overall rates of net community productivity regardless of the species of benthic primary producer.

In contrast to dissolved oxygen dynamics, exudates from non-calcifying algae strongly increased planktonic microbial DOC consumption rates to values that exceed the release rates of the exudates, leading to a net removal of DOC in turf and macro-algae (at least of the species measured here) dominated reef environments (Fig 3.E, Fig 6). Estimating rates of DO and DOC change in the investigated lagoons of Mo'orea based on reported benthic cover data (Turf 35\%; Macroalgae 35\%; Coral 22\%; Sand $8 \%$, see Methods above) yielded a net excess of oxygen production (+7.6 $\left.\mu \mathrm{mol} \mathrm{L} \mathrm{L}^{-1} \mathrm{~d}^{-1}\right)$ and net consumption of DOC $\left(-2.2 \mu \mathrm{mol} \mathrm{L}^{-1} \mathrm{~d}^{-1}\right)$. However, these broad extrapolations should be treated with caution as there may be important species specific rates of production and DOC release within each of the benthic functional groups that we have yet not accounted for.

\section{In-situ mesocosm fluxes}

To evaluate the calculations obtained from the beaker incubations, we compared our estimates of reef-scale ecosystem fluxes with results from in situ mesocosm incubations using cBITs. DO and temperature loggers deployed within each of these semi closed mesocosms showed that DO values significantly increased in all the tents containing coral (pairwise two-tailed t-test $\mathrm{p}<0.0033$ ) or turf algae (pairwise two-tailed t-test $\mathrm{p}<0.0001$ ) over a $24 \mathrm{~h}$ period. Tents deployed on sand however, showed no statistically significant changes in oxygen concentrations over a 24h interval (Fig 6). DOC concentrations increased on average in tents deployed above corals and sand flats and showed an average decrease in tents enclosing algae dominated communities. The magnitude and direction of DO and DOC fluxes matched those derived from extrapolations based on the bottle incubation experiments described above (See Fig 6). 


\section{Discussion}

Our study reports for the first time how the responses of different microbial compartments (benthic and planktonic) to benthic primary producer exudates contribute to the reef-scale community metabolism of oxygen and DOC. By coupling these responses with measurements of photosynthesis and exudate release by benthic producers, we are able to model the influence of benthic community structure on reef community metabolism. Previous work has described how antagonistic coral reef associated ecosystem engineers (Berkenbusch and Rowden 2003) like coral and non calcifying algae have the potential to alter biogeochemical cycling and microbial processes (Wild et al. 2011). While previous work has measured rates of benthic primary production (e.g. Wanders 1976, Hatcher 1990), organic matter release by benthic producers (e.g. Brylinsky 1977, Tanaka et al 2008, Muscatine et al. 1984) and subsequent exudate remineralization by the planktonic microbial community (e.g. Ferrier-Pagès et al. 2000, Haas et al. 2011), we believe our study is the first to address the cumulative effects of these processes over diurnal cycles and at a landscape scale to holistically estimate the effects of benthic primary producers on reef metabolism.

Similar to previous studies (Hatcher 1990, Wild et al. 2010, Haas et al. 2011), the algae investigated here (particularly the non-calcifying taxa) showed significantly higher rates of net primary production than the hermatypic coral. Concomitantly, the fleshy algae fixed more inorganic carbon during photosynthetic processes (estimated as higher DO production) and also exuded significantly higher amounts of dissolved organic carbon into their surrounding environment. DOC release rates of the different primary producers $(8-57 \mu \mathrm{mol}$ $\mathrm{dm}^{-2} \mathrm{~d}^{-1}$ ) were comparable to release rates previously published from reef locations around the world (Naumann et al. 2012, Red Sea corals: 6 - $56 \mu \mathrm{mol} \mathrm{dm}^{-2} \mathrm{~d}^{-1}$; Haas et al. 2010, Mexican Caribbean algae: 28 - $208 \mu \mathrm{mol} \mathrm{dm}^{-2} \mathrm{~d}^{-1}$, Haas et al. 2011, Central Pacific coral and macroalgae: $48-336 \mu \mathrm{mol} \mathrm{dm}^{-2} \mathrm{~d}^{-1}$ ). In the present study, over a full diurnal cycle, benthic primary producers released about $10 \%$ of their daily fixed carbon as DOC in the surrounding waters.

Responses of the associated microbial communities to these exudates varied widely and were dependent on the source of the exudates as well as the habitat that the microbes originated from. Contrary to previous studies which generally linked the abundance of highly productive macroalgae to an overall increase in net metabolic balance (Wanders 1976, Hatcher 1990), our study indicates that, as a result of subsequent increased remineralization of exudates by planktonic and benthic microbial communities, the estimated net oxygen production does not vary significantly between coral and algae dominated reef systems on a PeerJ reviewing PDF | (v2013:04:457:1:1:NEW 27 Jun 2013) 
community scale. Further, our results suggest that, with shifts from coral to algae dominated systems, dissolved organic carbon concentrations in the water column will decrease as a result of an elevated heterotrophic microbial community metabolism, congruent with demonstrated DOC depletion in shallow reefs (Nelson et al. 2011)

Results from the beaker incubations containing either benthic or planktonic microbes and seawater only showed that while the planktonic microbial community was consistently net heterotrophic the benthic microbial community metabolism was net autotrophic due to daytime photosynthesis, producing significantly higher amounts of oxygen during the daylight hours than it consumed over a $24 \mathrm{~h}$ period. Scaled volumetrically to the scale of a $3 \mathrm{~m}$ deep reef ecosystem, the effects of the respective net autotrophic benthic and net heterotrophic planktonic microbial communities had comparable magnitudes, resulting in a combined neutral net microbial community metabolism with no significant change of DOC and DO values over a whole diurnal cycle.

The introduction of exudates, however, had noticeable and significantly diverging influences on this balanced community metabolism. Coral exudates increased the net planktonic microbial community production, changing the net oxygen production towards an average positive balance during daylight hours. Coral exudates also enhanced the inherently autotrophic character of the microphytobenthos, such that at the reef scale coral exudates overall stimulated net ecosystem productivity (Fig 5). Significant increases in the abundance of autotrophic microbes as a result of available coral exudates have been previously reported (Ferrier-Pagès et al. 2000). Although the autotrophic cells do not necessarily rely on organic nutrients, it has been demonstrated that they can also take up DOM, such as amino acids, as an inorganic nutrient source (Flynn \& Butler 1986, Palenik \& Morel 1990). Autotrophic microbial biomass enhancement may thus be mediated by an increase in bioavailable inorganic nutrients, supplied by heterotrophic remineralization of coral exudates in the biocatalytic reef sands (Szmant et al. 1990, Schlichter \& Liebezeit 1991, Ferrier-Page et al. 2000, Wild et al. 2004a, 2005a). In contrast, addition of algal exudates, most noticeably exudates derived from turf algae, stimulated heterotrophic oxygen and organic carbon consumption rates by the planktonic and benthic microbial community, mediating an overall shift toward a significantly more heterotrophic microbial community metabolism. Although the changes in the combined microbial community metabolism did not outweigh the high oxygen production rates of benthic algae, the exudates did result in increased microbial DOC consumption which exceeded measured DOC exudation rates (Fig 3.A, 3.D and 3.E). When scaled to the $3 \mathrm{~m}$ deep reef ecosystem this imbalance resulted in a net bacterial carbon demand PeerJ reviewing PDF | (v2013:04:457:1:1:NEW 27 Jun 2013) 
which exceeded the rate of carbon exudation by algae, suggesting a possible mechanism for observed depletion of DOC in waters overlying the reef relative to oceanic inputs (Nelson et al. 2011). Our previous study conducted in this reef system demonstrated that exudates from fleshy macroalgae were enriched in specific carbohydrate components and were more labile than exudates derived from corals, fostering rapid but inefficient growth of primarily copiotrophic bacterioplankton in the surrounding water column. By facilitating the remineralization of semi-labile DOC inputs from the open ocean (sensu Carlson 2002) the high carbon demand of inefficient copiotrophic "super-heterotrophs" (Dinsdale and Rohwer 2010) may be a mechanism fueling the excessive carbon consumption rates estimated here and the subsequent depletion of DOC (Nelson et al. 2011) on reefs dominated by fleshy algae such as the backreef of Mo'orea.

In contrast, the shift towards a net autotrophic metabolism of the collective microbial community stimulated by coral exudates likely compensates for the initially lower photosynthetic oxygen production rates of corals compared to algae (Wanders 1976, Hatcher 1990). In our estimates this resulted in comparable net oxygen fluxes of the combined community metabolism in coral compared to algae dominated locations. Coral exudates facilitated changes in the microbial community metabolism towards higher production rates and led to an overall increase in DOC concentrations (resulting from net coral and microbial DOC release). Together these results suggest that reefs dominated by corals, by stimulating microbial primary production, may maintain comparable net ecosystem productivity to those dominated by fleshy algae, but additionally may maintain elevated levels of potentially labile DOC available for remineralization and recycling by microbial communities.

Our reef-scale estimates of benthic productivity and benthic and pelagic microbial metabolism from habitat-specific bottle incubations were validated by in situ measurements using contained benthic incubation tents (cBITs; Fig 1); net metabolic balances of both oxygen and DOC assessed in benthic tents over a whole diurnal cycle showed the same trends as suggested by the reef wide calculations derived from our incubation experiments (Fig 6). This study may thus suggest potential explanations for previously observed discrepancies of primary producer effects on in situ values of DO and DOC concentrations. For example, while some studies identified higher net primary production, and concomitant $\mathrm{O}_{2}$ production, of fleshy algae compared to corals (Wanders 1976, Hatcher 1990, Done 1992, Haas et al. 2011), in situ measurements revealed lower oxygen concentrations in algae dominated areas compared to reef locations with high cover of hermatypic corals or other calcifying organisms (Haas et al. 2010b, Niggl et al. 2010). This is also the case for the proposed effects of the PeerJ reviewing PDF | (v2013:04:457:1:1:NEW 27 Jun 2013) 
primary producer communities on surrounding DOC concentrations. While multiple studies in various coral reef systems have shown that coral reef associated primary producers, and particularly fleshy macro- and turf algae, release a noticeable portion of their photosynthetically fixed carbon as dissolved material into their surroundings (Wild et al. 2010, Haas et al. 2011), recent in situ assessments of tropical reef environments identified significantly lower DOC concentrations associated with higher algal abundance (Dinsdale et al. 2008; Nelson et al 2011) throughout the tropical Pacific. This apparent discrepancy has been suggested to be caused by a co-metabolism of refractory carbon that occurs when microbes are given an excess labile carbon (Carlson et al. 2002, Dinsdale et al 2008, Nelson et al. 2011). The differences between the direct influences of the different primary producers on oxygen and DOC (i.e. high production rates of non-calcifying algae) and the resulting values measured in situ values (low DO/DOC concentrations associated with high algal cover) may be explained by the unaccounted-for influences of algal and coral exudates on collective microbial metabolism demonstrated here.

Beyond the direct effects of primary producers and the indirect effects of microbes on key environmental parameters (DO, DOC), this study also shows noticeable influences of specific primary producer exudates on the community metabolism and the abundance of microbes in the different reef habitats (benthic vs. planktonic). While turf algal exudates led to significant increases in the abundance of the collectively net heterotrophic microbial community, they simultaneously mediated a significant decrease of bacterial growth rates in the generally net autotrophic benthic environment. Coral exudates in contrast showed no considerable effect on cell abundance in the planktonic environment, but fostered significantly higher growth rates than all other treatments in the predominately autotrophic benthic associated microbial community.

A possible caveat of our study is that we assumed concentration independency on influences of the different exudates on the microbial communities. Although the data supports this assumption partly as there is no direct relation between the starting DOC concentrations and the microbial oxygen draw down rates, and a related study (Nelson et al. 2013) showed that the composition of the respective exudates has a significant influence on the microbial community, there may be concentration thresholds at which the overall amount of the organic carbon supplied to the system will play a role in microbial metabolism. Nevertheless, the fact that the contrasting effects of the exudates derived from coral and algae change the metabolism in the planktonic and benthic environment relative to the controls regardless of the amount of exudate used suggests that the mechanisms described above are of ecological PeerJ reviewing PDF | (v2013:04:457:1:1:NEW 27 Jun 2013) 
significance. Additional validation of these mechanisms is given with the data collected from the in situ cBITs..

\section{Conclusion}

This study primarily highlights the variability of benthic primary producer influences in different ecosystem compartments. It indicates their diverging effects on planktonic and benthic microbial ecology and subsequently on biogeochemical resources. The shift from net autotrophic towards net heterotrophic microbial community metabolism, accompanying changes from coral to algal dominance, may thereby have potential negative implications on energy transfer to higher trophic levels (McDole et al 2012). Our results suggest that the bioavailable energy (DOC) provided by the macrobial photosynthetic organisms will not be able to support the multitude of trophic levels found in this otherwise oligotrophic coral reef environment, but rather fuels a short linked and inefficient (Haas et al. 2011, Nelson et al. 2013) microbial metabolism. Finally, our use of controlled incubations, coupled with in situ mesocosm experiments, provides the first comprehensive view of benthic primary producer-induced, and microbially-mediated alterations of biochemical cycling over diurnal cycles in both benthic and pelagic shallow reef environments. While it is uncommon for researchers to simultaneously assess the independent and combined contribution of macroand micro- organisms to reef-scale metabolism, our results suggest that this approach will be necessary if we are to accurately predict how reef communities will change in response to the multitude of global and local stressors currently impacting them.

\section{Summary}

The following collection of studies supports the idea that the microbial and macrobial community are strongly interrelated and subjected to positive feedback loops in which contribute to phase shifts from coral to algal dominance.

Microbes inhabiting coral surfaces are subjected to shifts in community composition and elevated activity in response to increased availability of algae derived DOM. This increased microbial activity, facilitated by bioavailable algae derived OM, has been identified as a key mechanism leading to coral mortality. First, Kuntz et al. (2005) and Kline et al. (2006) showed that elevated concentrations of organic compounds were more detrimental to coral health than increased availability of inorganic nutrients. Concurrently, Smith et al. (2006) conducted an empirical study which demonstrated that coral mortality was mediated by algal released dissolved compounds which induced microbe facilitated hypoxia. PeerJ reviewing PDF | (v2013:04:457:1:1:NEW 27 Jun 2013) 
Supporting results have been provided by Barott et al. (2009) and a recent study by Morrow et al. (2012) who identified consistent patterns in physiology and microbial community differentiation across different types of coral-algal competitive interactions. Here turf- or macroalgae interactions with corals created a zone of hypoxia and altered pigmentation in the coral tissue. In the companion manuscript (Haas et al.) we can provide the first direct visualization of oxygen gradients originating from corals and algae, as well as at the interfaces. The study shows 2 dimensional images of oxygen gradients over time in varying flow conditions and can thereby provide compelling evidence for the existence of hypoxic zones in coral-algae interaction processes. By using oxygen optodes as biological sensors, Gregg et al. (companion manuscript), revealed that in these processes the source of DOC, rather than the microbial community is the driving factor for microbial oxygen drawdown.

On a larger scale Dinsdale et al. (2008) described an increase of the microbial density by an order of magnitude from islands dominated by hermatypic corals and coralline algae towards islands dominated by fleshy macro- and turf algae. This study also demonstrated that on islands with high cover of fleshy macro- and turf algae the microbial community was dominated by heterotrophs, including a large percentage of potential pathogens. Adding to this, Nelson et al. (2013) showed that, in contrast to coral exudates, which facilitated high microbial diversity with few virulence factors, macroalgal exudates selected for less diverse communities heavily enriched in copiotrophic lineages, containing pathogens with increased virulence factors. These copiotrophic lineages, which are selected for in energy-rich surroundings resulting from labile, algae derived organic material have been previously described as “super-heterotrophs” (Dinsdale and Rohwer 2010).

This shift towards higher abundance of planktonic microbes has been described in a recent study by McDole et al. (2012) as “Microbialization”. Here, a microbialization score was applied to each site representing the percentage of the microbial metabolic energy consumption opposed to macro-organism facilitated energy fluxes in an ecosystem. A survey of 99 locations across the tropical Pacific demonstrated a strong correlation between these reef microbialization scores and human impact. In impacted systems McDole et al. (2012) identified a reallocation of bioavailable energy, provided by the primary producers from more complex organisms (e.g. fish biomass) to microbes. While McDole et al. (companion manuscript) suggest that in stages of intermediate degradation (noticeable, but limited human impact, e.g. Molokai, Hawaii / Saipan, Northern Mariana Islands) a disproportionately high amount of energy is dissipated by autotrophic microbes, they further suggest that in severely degraded reef systems (high human impact, e.g. Oahu \& Niihau, Hawaii), pathways of energy PeerJ reviewing PDF | (v2013:04:457:1:1:NEW 27 Jun 2013) 
flow are reestablished through heterotrophic microbes with more pathogen-like or copiotrophic growth strategies.

Collectively, these studies show that in coral reef systems, organic matter dynamics are tightly coupled with the benthic primary producers- and the associated microbial community. Further it becomes evident, that these factors strongly influence each other and may create positive feedback loops by a) fostering ineffective and more pathogenic microbial communities, which b) facilitate regions of decreased oxygen availability through metabolic activities, and c) alter the transfer of energy to higher trophic levels, during shifts from coral to algal dominance on tropical reefs.

\section{References}

Alongi DM. 1994. Zonation and seasonality of benthic primary production and community respiration in tropical mangrove forests. Oecologia 98:320-327.

Azam LIF. 1983. The ecological role of water-column microbes. Marine Ecology Progress Series 1:257-263.

Barott K, Smith JE, Dinsdale E, Hatay M, Sandin S, Rohwer FL. 2009. Hyperspectral and physiological analyses of coral-algal interactions. PLoS ONE 4:e8043. doi:10.1371/journal.pone.0008043

Berkenbusch K, Rowden AA. 2003. Ecosystem engineering-moving away from" just-so" stories. New Zealand Journal of Ecology 27:67-73.

Boucher G, Clavier J, Hily C, Gattuso JP. 1998. Contribution of soft-bottoms to the community metabolism (primary production and calcification) of a barrier reef flat (Moorea, French Polynesia). Journal of Experimental Marine Biology and Ecology. 225:269-283.

Brown BE, Bythell JC. 2005. Perspectives on mucus secretion in reef corals. Marine Ecology Progress Series. 296:291-309.

Brylinsky M. 1977. Release of dissolved organic matter by some marine macrophytes. Marine Biology 39:213-220.

Capone DG, Dunham SE, Horrigan SG, Duguay LE. 1992 Microbial nitrogen transformations in unconsolidated coral reef sediments. Marine Ecology Progress Series 80:75-88.

Carlson CA, Giovannoni SJ, Hansell DA, Goldberg SJ, Parsons R, Otero MP, Vergin K, Wheeler BR. 2002. Effect of nutrient amendments on bacterioplankton production, community structure, and DOC utilization in the northwestern Sargasso Sea. Aquatic Microbial Ecology 30:19-36.

Carlson CA, Giovannoni SJ, Hansell DA, Goldberg SJ, Parsons R, Vergin K. 2004. Interactions between DOC, microbial processes, and community structure in the mesopelagic zone of the northwestern Sargasso Sea. Limnology and Oceanography 49:1073-1083.

Carlson CA, Hansell DA, Nelson NB, Siegel DA, Smethie WMJ, Khatiwala S, Meyers MM, Halewood E. 2010. Dissolved organic carbon export and subsequent remineralization in the mesopelagic and bathypelagic realms of the North Atlantic basin. Deep Sea Research Part II: Topical Studies in Oceanography 57: 1433-1445.

Clavierll J, Garrigue C. 1999. Annual sediment primary production and respiration in a large

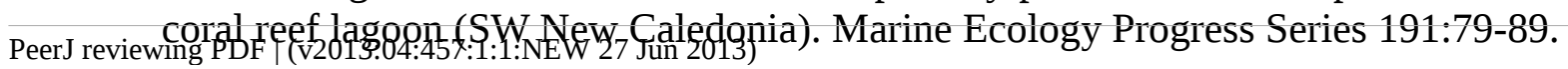


Crossland CJ. 1987. In situ release of mucus and DOC-lipid from the corals Acropora variabilis and Stylophora pjstillata. Coral Reefs 6:35-42.

de Goeij JM, Moodley L, Houtekamer M, Carballeira NM, van Duyl FC (2008) Tracing C-13-enriched dissolved and particulate organic carbon in the bacteria-containing coral reef sponge Halisarca caerulea: evidence for DOM feeding. Limnology and Oceanography 53:1376-1386.

Dinsdale EA, Pantos O, Smriga S, Edwards RA, Angly F, Wegley L, Hatay M, Hall D, Brown E, Haynes M, Krause L, Sala E, Sandin SA, Thurber RV, Willis BL, Azam F, Knowlton N, Rohwer F. 2008. Microbial ecology of four coral atolls in the Northern Line Islands. PloSOne 3:e1584.

Dinsdale EA, Rohwer F. 2010. Fish or germs? Microbial dynamics associated with changing trophic structures on coral reefs. In: Dubinsky Z, Stambler N, eds. Coral Reefs: An Ecosystem in Transition. Springer

Done TJ. 1992. Phase shifts in coral reef communities and their ecological significance. Hydrobiologia 247:121-132.

Done TJ, Ogden JC, Wiebe WJ, Rosen BR. 1996. Biodiversity and ecosystem function of coral reefs. In: Mooney HA, Cushman JH, Medina E, Sala OE, Schulze ED. eds. Functional Roles of Biodiversity: A Global Perspective. SCOPE. John Wiley and Sons.

Ferrier-Pagès C, Gattuso JP, Cauwet G, Jaubert J, Allemand D. 1998. Release of dissolved organic carbon and nitrogen by the zooxanthellate coral Galaxea fascicularis. Marine Ecology Progress Series 172:265-274.

Ferrier-Pagès C, Leclercq N, Jaubert J, Pelegrí SP. 2000. Enhancement of pico-and nanoplankton growth by coral exudates. Aquatic Microbial Ecology 21:203-209.

Flynn KJ, Butler I. 1986. Nitrogen sources for the growth of microalgae: role of dissolved free amino acids. Marine Ecology Progress Series 34:281-304.

Gordon DC Jr. 1971. Organic carbon budget of Fanning Island Lagoon. Pacific Science 25:222-227.

Haas AF, Naumann MS, Struck U, Mayr C, el-Zibdah M, Wild C. 2010a. Organic matter release by coral reef associated benthic algae in the Northern Red Sea. Journal of Experimental Marine Biology and Ecology 389:53-60.

Haas AF, Jantzen C, Naumann MS, Iglesias-Prieto R, Wild C. 2010b. Organic matter release by the dominant primary producers in a Caribbean reef lagoon: implication for in situ $\mathrm{O}_{2}$ availability. Marine Ecology Progress Series 409:27-39.

Haas AF, Rohwer F, Carlson C, Nelson C, Wegley L, Leichter J, Smith JE. 2011. Effects of coral reef benthic primary producers on dissolved organic carbon and microbial activity. PLoSOne 6:e27973.

Hansen JA, Alongi DM, Moriarty DJW, Pollard PC. 1987. The dynamics of benthic microbial communities at Davies Reef, central Great Barrier Reef. Coral Reefs 6:63-70.

Hatcher BG. 1990. Coral reef primary productivity. A hierarchy of pattern and process. Trends in Ecology \& Evolution 5:149-155.

Heil CA, Chaston K, Jones A, Bird P, Longstaff B, Costanzo S, Dennison WC. 2004. Benthic microalgae in coral reef sediments of the southern Great Barrier Reef, Australia. Coral Reefs 23:336-343.

Hench JL, Leichter JJ, Monismith SG. 2008. Episodic circulation and exchange in a wave-driven coral reef and lagoon system. Limnology \& Oceanography 53:2681-2694.

Hewson I, Fuhrman JA. 2006. Spatial and vertical biogeography of coral reef sediment bacterial and diazotroph communities. Marine Ecology Progress Series 306:79-86.

Hoegh-Guldberg O, Mumby PJ, Hooten AJ, Steneck RS, Greenfield P, Gomez E, Harvell CD, Sale PF, Edwards AJ, Caldeira K, Knowlton N, Eakin CM, Iglesias-Prieto R, Muthiga N,Bradbury RH, Dubi A, Hatziolos ME. 2007. Coral reefs under rapid climate change

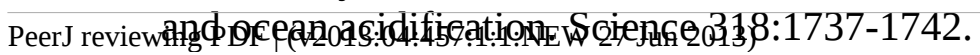


Hughes T, Rodrigues M, Bellwood D, Ceccarelli D, Hoegh-Guldberg O, McCook L, Moltschaniwskyj N, Pratchett M, Steneck R, Willis B. 2007. Phase shifts, herbivory, and the resilience of coral reefs to climate change. Current Biology 17:360-365.

Jones CG, Lawton JH, Shachak M. 1997. Positive and negative effects of organisms as physical ecosystem engineers. Ecology 78:1946-1957.

Kline DI, Kuntz NM, Breitbart M, Knowlton N, Rohwer F. 2006. Role of elevated organic carbon levels and microbial activity in coral mortality. Marine Ecology Progress Series 314:119-125.

Kuntz, N.M., Kline, D.I., Sandin, S.A., Rohwer, F. 2005. Pathologies and mortality rates caused by organic carbon and nutrient stressors in three Caribbean coral species. Marine Ecology Progress Series 294:173-180.

Lee S, Fuhrman JA. 1987. Relationships between biovolume and biomass of naturally derived marine bacterioplankton. Applied Environmental Microbiology 53:1298-1303.

McCook LJ. 1999. Macroalgae, nutrients and phase shifts on coral reefs: scientific issues and management consequences for the Great Barrier Reef. Coral Reefs 18:357-367.

McDole T, Nulton J, Barott KL, Felts B, Hand C, Hatay M, Lee H, Nadon MO, Nosrat B, Salamon P, Bailey B, Sandin SA, Vargas-Angel B, Youle M, Zgliczynski BJ, Brainard RE, Rohwer F. 2012. Assessing coral reefs on a Pacific-wide scale using the microbialization score. PloSOne 7:e43233.

McManus JW, Polsenberg JF. 2004. Coral-algal phase shifts on coral reefs: ecological and environmental aspects. Progress in Oceanography 60:263-279.

Morrow KM, Ritson-Williams R, Ross C, Liles MR, Paul VJ. 2012. Macroalgal extracts induce bacterial assemblage shifts and sublethal tissue stress in Caribbean corals. PloSOne 7:e44859.

Muscatine L, Falkowski PG, Porter JW, Dubinsky Z. 1984. Fate of photosynthetic fixed carbon in light-and shade-adapted colonies of the symbiotic coral Stylophora pistillata. Proceedings of the Royal Society of London. Series B. Biological Sciences, 222:181-202.

Naumann MS, Richter C, Mott C, el-Zibdah M, Manasrah R, Wild C. 2012. Budget of coral-derived organic carbon in a fringing coral reef of the Gulf of Aqaba, Red Sea. Journal of Marine Systems 105-108:20-29

Nelson CE, Alldredge AL, McCliment EA, Amaral-Zettler LA, Carlson CA. 2011. Depleted dissolved organic carbon and distinct bacterial communities in the water column of a rapid-flushing coral reef ecosystem. The ISME Journal 5:1374-1387.

Nelson CE, Goldberg SJ, Kelly LW, Haas AF, Smith JE, Rohwer F, Carlson CA. 2013. Coral and macroalgal exudates vary in neutral sugar composition and differentially enrich reef bacterioplankton lineages. The ISME journal doi:10.1038/ismej.2012.161

Niggl W, Haas AF, Wild C. 2010. Benthic community composition affects $\mathrm{O}_{2}$ availability and variability in a Northern Red Sea fringing reef. Hydrobiologia 644:401-405.

Odum EP. 1968. Energy flow in ecosystems: a historical review. American Zoologist 8:11-18.

Paine RT. 1980. Food Webs: Linkage, interaction strength and community infrastructure. Journal of Animal Ecology 49:666-685.

Palenik B, Morel FMM. 1990. Amino acid utilization by marine phytoplankton: a novel mechanism. Limnology and Oceanography 35:260-269.

Rasheed M, Wild C, Franke U, Huettel M. 2004. Benthic photosynthesis and oxygen consumption in permeable carbonate sediments at Heron Island, Great Barrier Reef, Australia. Estuarine, Coastal and Shelf Science 59:139-150.

Rosenberg E, Koren O, Reshef L, Efrony R, Zilber-Rosenberg I. 2007. The role of microorganisms in coral health, disease and evolution. Nature Reviews Microbiology 5:355-362. 
Rusch A, Hannides AK, Gaidos E. 2009. Diverse communities of active bacteria and archaea along oxygen gradients in coral reef sediments. Coral Reefs 28:15-26.

Scheffers SR, Nieuwland G, Bak RPM, Van Duyl FC. 2004. Removal of bacteria and nutrient dynamics within the coral reef framework of Curaçao (Netherlands Antilles). Coral Reefs, 23:413-422.

Schlichter D, Liebezeit G. 1991. The natural release of amino acids from the symbiotic coral Heteroxenia fuscescens (Ehrb.) as a function of photosynthesis. Journal of Experimental Marine Biology and Ecology 150:83-90.

Schöttner SI, Pfitzner B, Grünke S, Rasheed M, Wild C, Ramette A. 2011. Drivers of bacterial diversity dynamics in permeable carbonate and silicate coral reef sands from the Red Sea. Environmental Microbiology 13:1815-1826.

Sjöling S, Mohammed SM, Lyimo TJ, Kyaruzi JJ. 2005. Benthic bacterial diversity and nutrient processes in mangroves: impact of deforestation. Estuarine, Coastal and Shelf Science 63:397-406.

Smith JE, Shaw M, Edwards RA, Obura D, Pantos O, Sala E, Sandin SA, Smriga S, Hatay M, Rohwer FL. 2006. Indirect effects of algae on coral: algae-mediated, microbe-induced coral mortality. Ecology Letters 9:835-845.

Sørensen K, Glazer B, Hannides A, Gaidos E. 2007. Spatial structure of the microbial community in

sandy carbonate sediment. Marine Ecology Progress Series 346:61-74.

Sournia A. 1976. Oxygen metabolism of a fringing reef in French Polynesia. Helgoländer Wissenschaftliche Meeresuntersuchungen 28:401-410.

Szmant AM, Ferrer LM, FitzGerald LM. 1990. Nitrogen excretion and 0:N ratios in reef corals: evidence for conservation of nitrogen. Marine Biology 104:119-127.

Tanaka Y, Miyajima T, Koike I, Hayashibara T, Ogawa H. 2008. Production of dissolved and particulate organic matter by the reef-building corals Porites cylindrica and Acropora pulchra. Bulletin of Marine Science 82:237-245.

Valiela I. 1984. Marine ecological processes. Springer-Verlag, New York.

Wanders JBW. 1976. The role of benthic algae in the shallow reef of Curacao (Netherlands Antilles). I: Primary productivity in the coral reef. Aquatic Botany 2:235-270.

Werner U, Blazejak A, Bird P, Eickert G, Schoon R, Abed RM, Bissett A, de Beer D. 2008. Microbial photosynthesis in coral reef sediments (Heron Reef, Australia). Estuarine, Coastal and Shelf Science 76:876-888.

Wild C, Huettel M, Klueter A, Kremb SG, Rasheed M, Jørgensen BB. 2004a. Coral mucus functions as an energy carrier and particle trap in the reef ecosystem. Nature 428:66-70.

Wild C, Rasheed MY, Werner U, Franke U, Johnstone R, Huettel M. 2004b. Degradation and mineralization of coral mucus in reef environments. Marine Ecology Progress Series 267:159-171.

Wild C, Woyt H, Huettel M. 2005a. Influence of coral mucus on nutrient fluxes in carbonate sediments. Marine Ecology Progress Series 287:87-98.

Wild C, Rasheed MY, Jantzen C, Cook P, Struck U, Huettel M, Boetius A. 2005b. Benthic metabolism and degradation of natural particulate organic matter in silicate and carbonate sands of the Northern Red Sea. Marine Ecology Progress Series 298: 69-78.

Wild C, Haas AF, Naumann M, Mayr C, el-Zibdah M. 2009. Comparative investigation of organic matter release by corals and benthic reef algae - implications for pelagic and benthic microbial metabolism. Proceedings of the 11th International Coral Reef Symposium, Ft. Lauderdale, USA: 1319-1323

Wild C, Niggl W, Naumann MS, Haas AF. 2010. Organic matter release by Red Sea coral reef organisms - potential effects on microbial activity and in-situ $\mathrm{O}_{2}$ availability. Marine Ecology Progress Series 411:61-71. 
Wild C, Hoegh-Guldberg O, Naumann M, Colombo-Pallotta MF, Ateweberhan, M., Fitt WK, Iglesias-Prieto R, Palmer C, Bythell JC, Ortiz JC, Loya Y, van Woesik R. 2011. Climate change impedes scleractinian corals as primary reef ecosystem engineers. Marine \& Freshwater Research 62: 205-215.

\section{Figure legends}

Fig 1: cBIT deployed in situ over different benthic communities (examples bottom left to right: coral dominated, algae dominated, sand) with data logger (A) and circulation pump (B) connected to a Niskin sampling bottle (C)

Fig 2: Diurnally resolved direct effects of A) different primary producer functional groups on surrounding DO and DOC concentrations (surface area corrected) and effects facilitated by B) the pelagic and $\mathrm{C}$ ) benthic microbial communities as response to the respective exudates. Bars show mean values with standard error whiskers. Treatments with the same letter are not significantly different at $\alpha=0.05$.

Fig 3: Daily net fluxes of DO and DOC per $\mathrm{m}^{2}$ reef area dominated by the respective primary producer functional group. A) Changes facilitated directly by the producers B) Fluxes facilitated by the pelagic and C) Benthic microbial community as a response to the respective exudates. D) Combined pelagic and benthic microbial fluxes and E) combined net producer and, responding to their respective exudates, microbially facilitated fluxes. Bars show mean values with standard error whiskers. Treatments with the same letter are not significantly different at $\alpha=0.05$.

Fig 4: Bacterial growth rates in the respective exudate incubations. A) raw values, B) light phase resolved pelagic and C) benthic response, and D) combined pelagic and benthic growth over a whole $24 \mathrm{~h}$ time period.

Fig 5: Schematic model of exudate influences on benthic and pelagic microbial community metabolism. Without exudates present the net heterotrophic pelagic and net autotrophic

Peer renthic miching Pfobial community exhibit comparable magnitudes in their opposing influences on 
DO availability. Coral exudates facilitate a shift towards a net autotrophic system by increasing the net production of the benthic and decreasing the net consumption of the pelagic community. In contrast, algal exudates facilitate a shift towards a net heterotrophic system by decreasing the net production of the benthic and increasing the net consumption of the pelagic microbial community.

Fig 6: Calculated change for the respective benthic cover on a lagoonal scale compared to in situ cBIT community metabolism measurements. Bars show mean values with standard error whiskers. Treatments with the same letter are not significantly different at $\alpha=0.05$.

\section{Supplementary Material}

Fig S1: Examples of DO fluxes assessed by autonomously working data loggers in cBITs over a 48h period. Red line shows values from 0 - 24h, blue line from $24-48 \mathrm{~h}$. Decreases over $24 \mathrm{~h}$ at a given time point are highlighted by a red area, increases by blue. Lower panels show change at each the respective daytime over $24 \mathrm{~h}$. Mean change is indicated by the dotted line.

Fig S2) Raw values of DO measurements in dark and daylight incubations over the period exposed to the respective light conditions

Fig S3) Raw values of DOC measurements in dark and daylight incubations over the period exposed to the respective light conditions 


\section{Figure 1}

Tent setup

cBIT deployed in situ over different benthic communities (examples bottom left to right: coral dominated, algae dominated, sand) with data logger (A) and circulation pump (B) connected to a Niskin sampling bottle (C). 


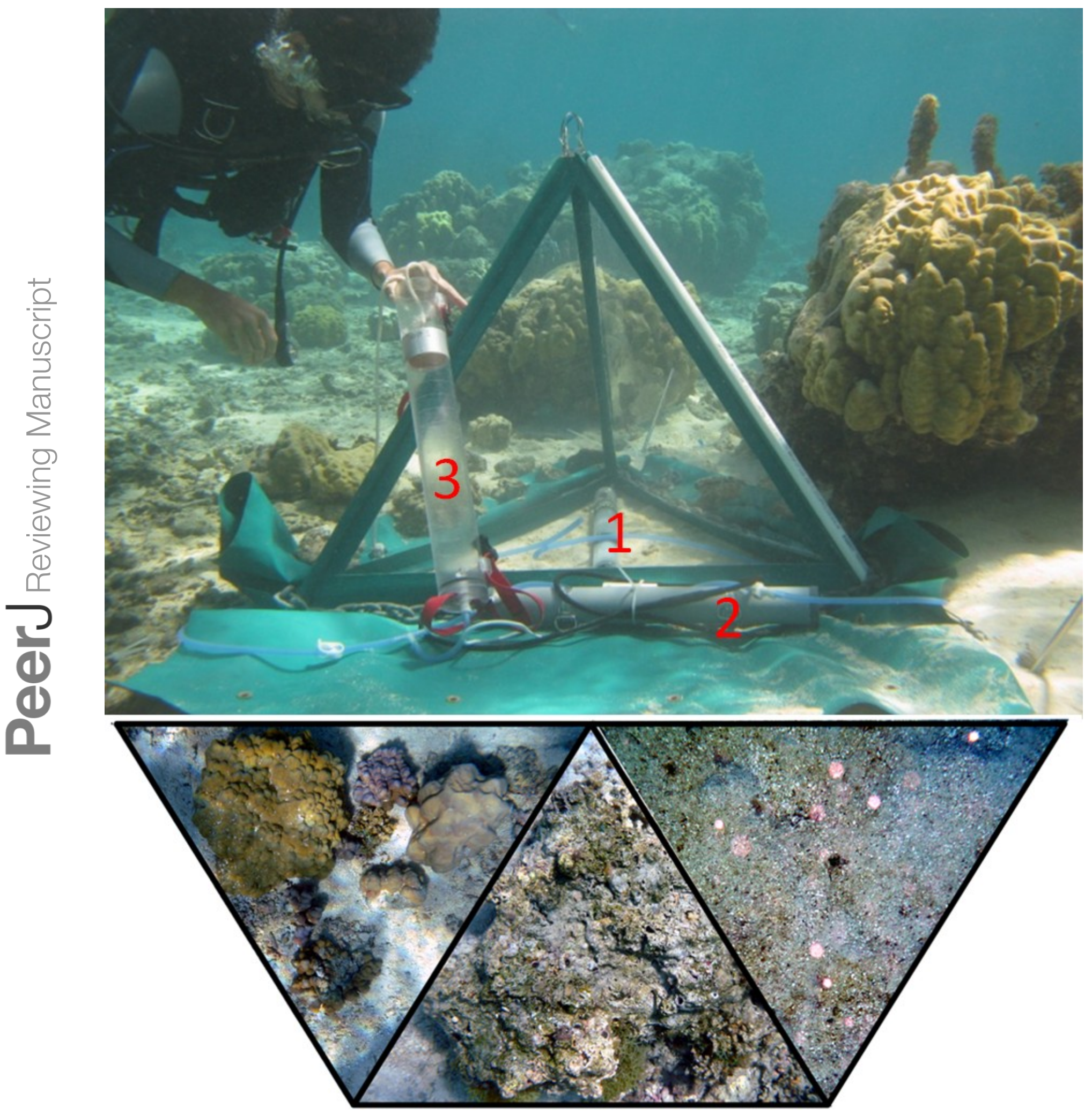




\section{Figure 2}

Diurnally resolved responses

Diurnally resolved direct effects of A) different primary producer functional groups on surrounding DO and DOC concentrations (surface area corrected) and effects facilitated by B) the pelagic and C) benthic microbial communities as response to the respective exudates. Bars show mean values with standard error whiskers. Treatments with the same letter are not significantly different at $\alpha=0.05$. 
DO

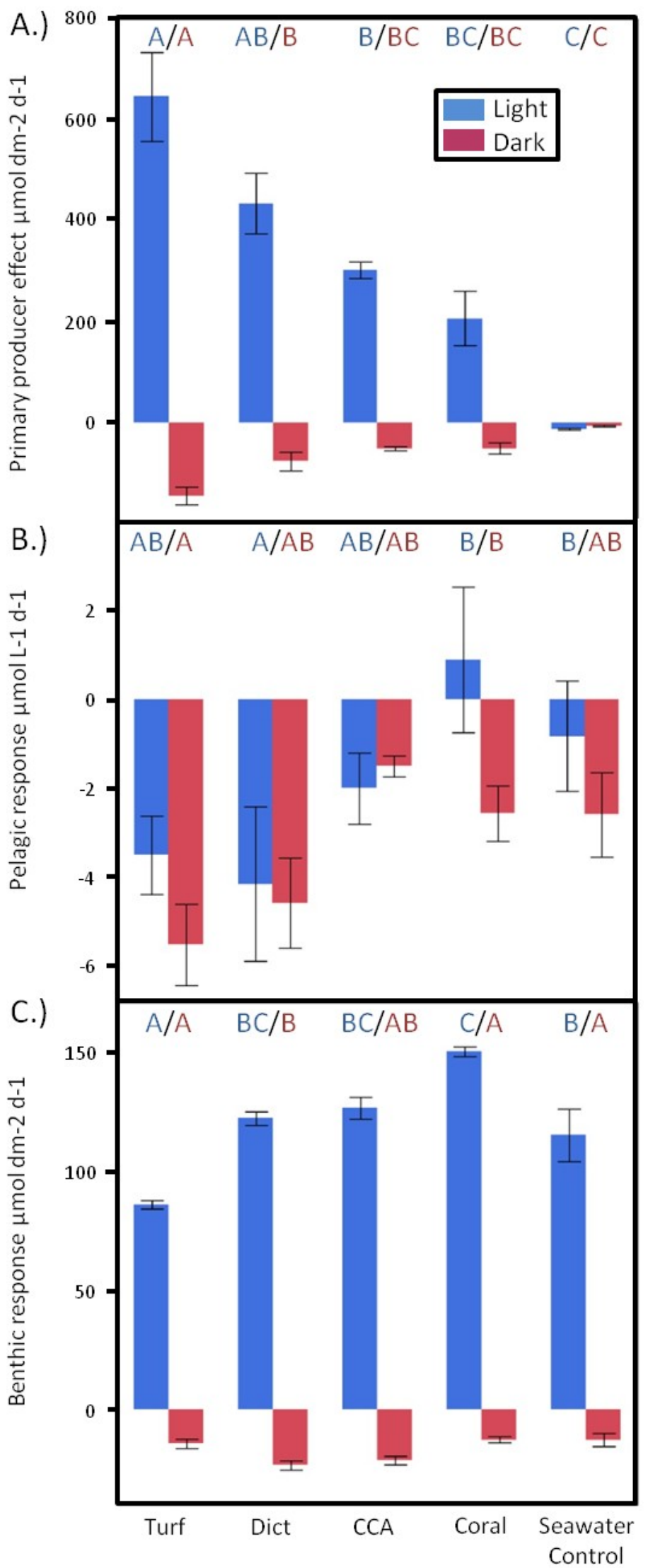

DOC

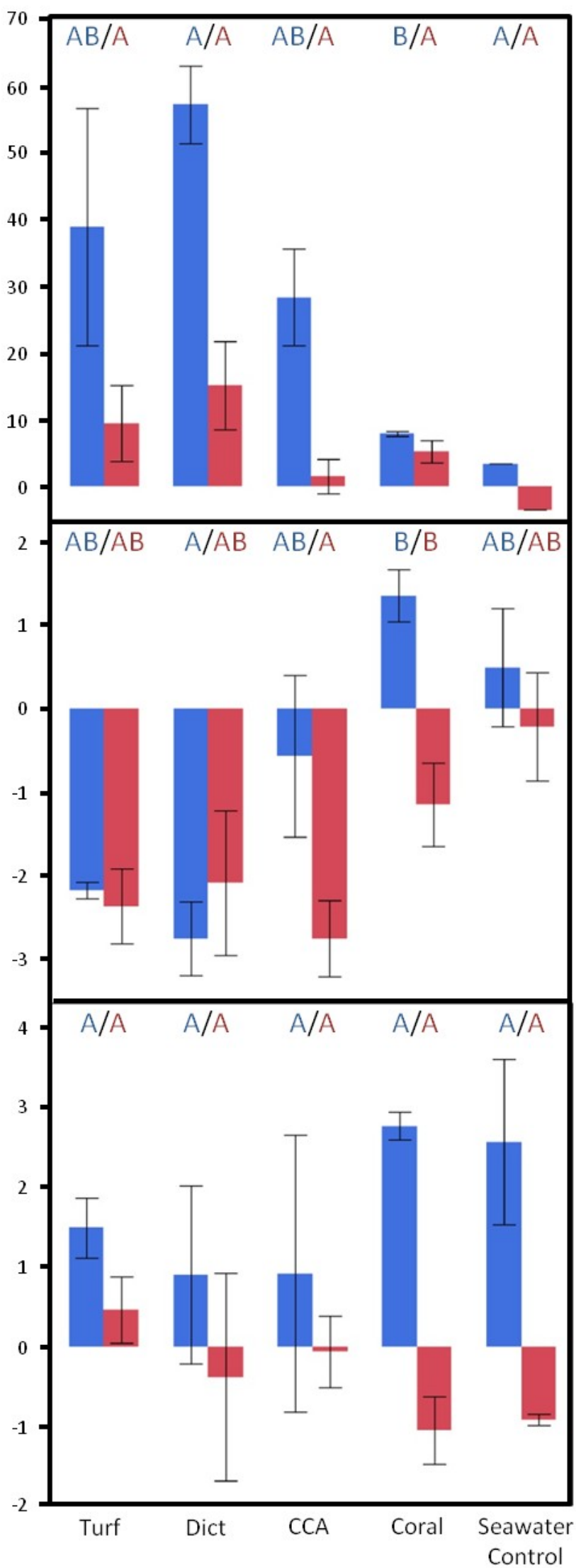




\section{Figure 3}

Net responses

Daily net fluxes of DO and DOC per $\mathrm{m}^{2}$ reef area dominated by the respective primary producer functional group. A) Changes facilitated directly by the producers B) Fluxes facilitated by the pelagic and C) Benthic microbial community as a response to the respective exudates. D) Combined pelagic and benthic microbial fluxes and E) combined net producer and, responding to their respective exudates, microbially facilitated fluxes. Bars show mean values with standard error whiskers. Treatments with the same letter are not significantly different at $\alpha=0.05$. 


\section{Figure 4}

\section{Microbial growth rates}

Bacterial growth rates in the respective exudate incubations. A) raw values, B) light phase resolved pelagic and C) benthic response, and D) combined pelagic and benthic growth over a whole $24 \mathrm{~h}$ time period.
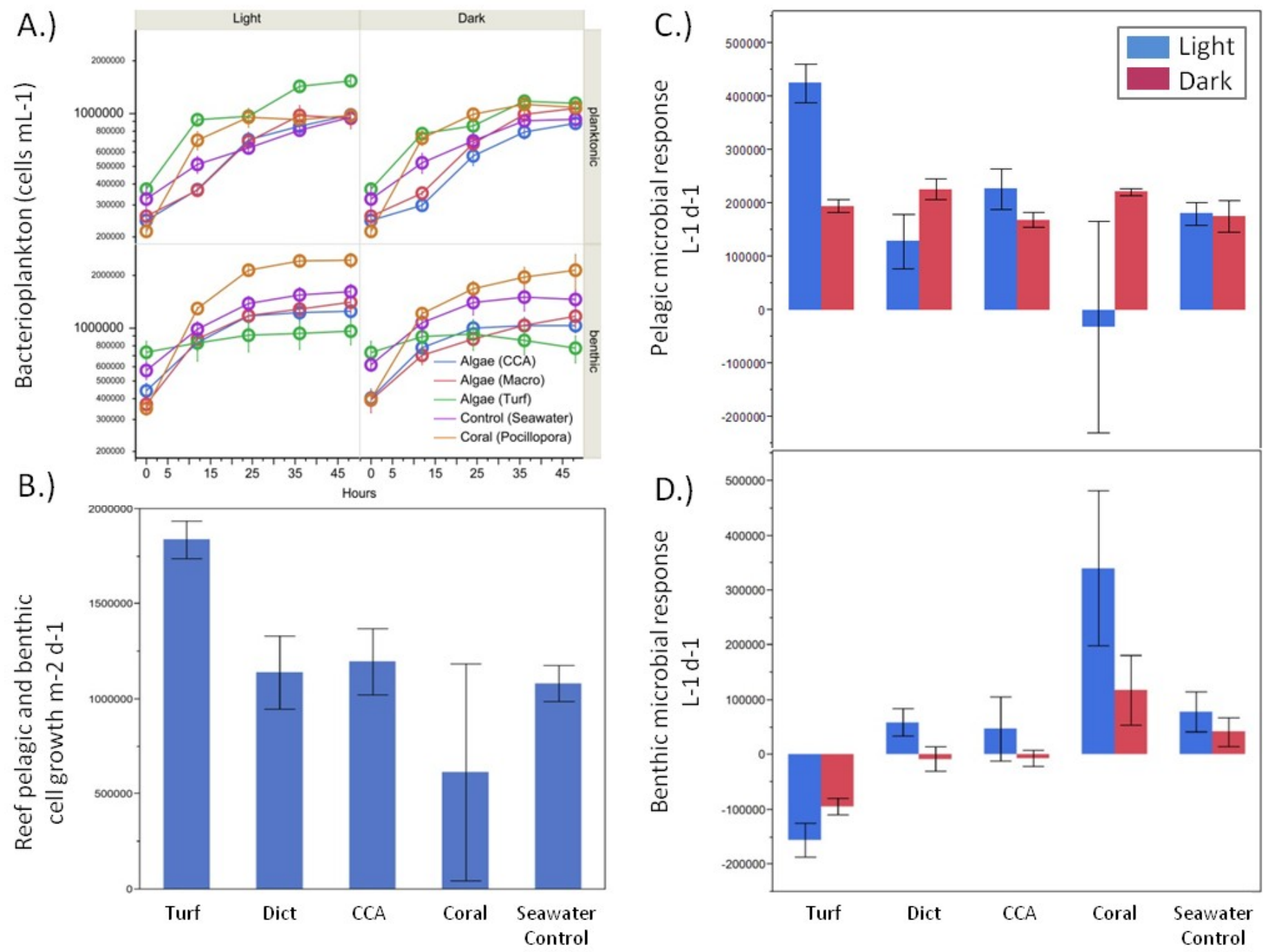


\section{Figure 5}

Exudate influences

Schematic model of exudate influences on benthic and pelagic microbial community metabolism. Without exudates present the net heterotrophic pelagic and net autotrophic benthic microbial community exhibit comparable magnitudes in their opposing influences on DO availability. Coral exudates facilitate a shift towards a net autotrophic system by increasing the net production of the benthic and decreasing the net consumption of the pelagic community. In contrast, algal exudates facilitate a shift towards a net heterotrophic system by decreasing the net production of the benthic and increasing the net consumption of the pelagic microbial community.

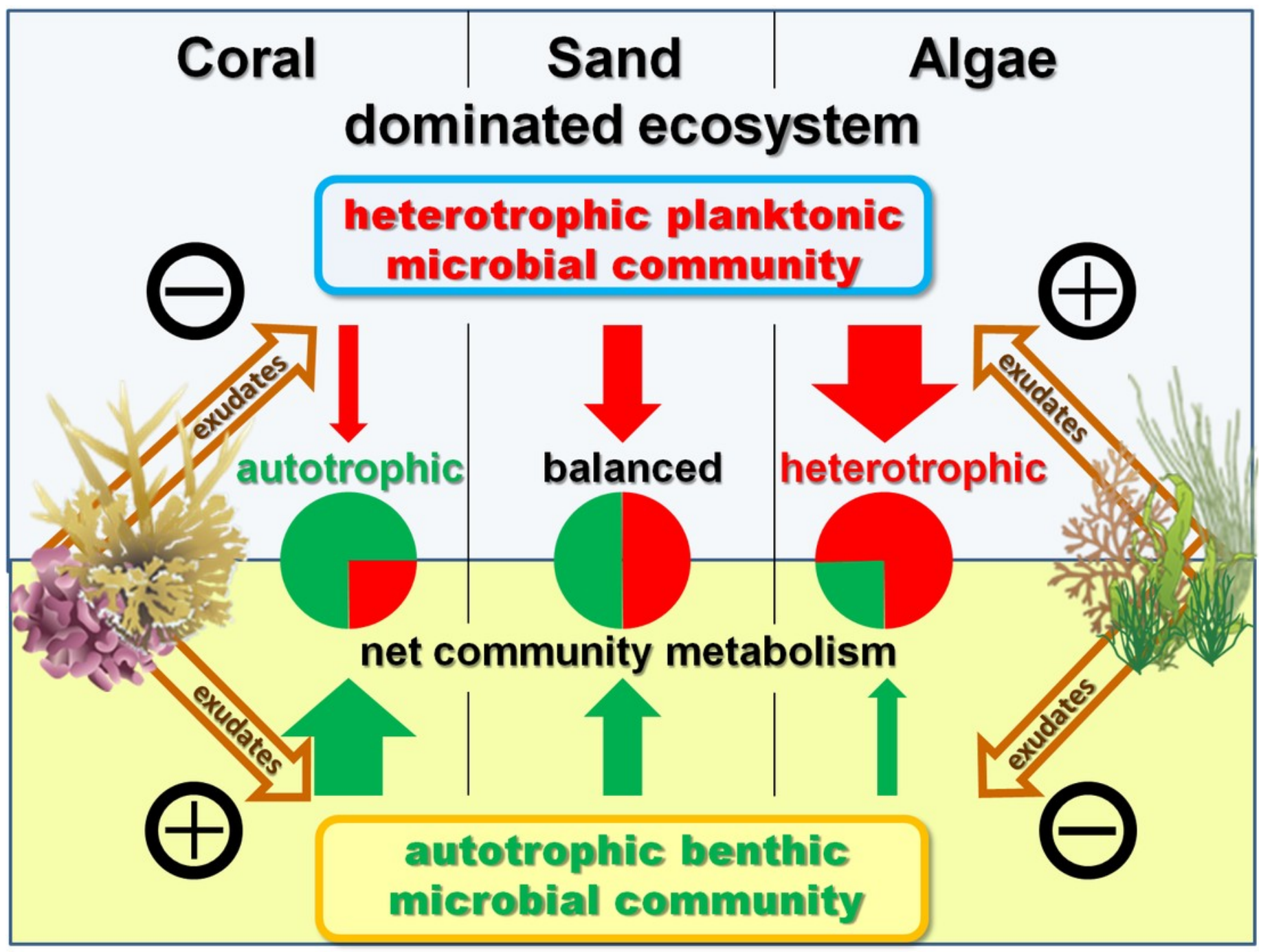




\section{Figure 6}

Beaker incubation to tent comparison

Calculated change for the respective benthic cover on a lagoonal scale compared to in situ cBIT community metabolism measurements. Bars show mean values with standard error whiskers.

Treatments with the same letter are not significantly different at $\alpha=0.05$.

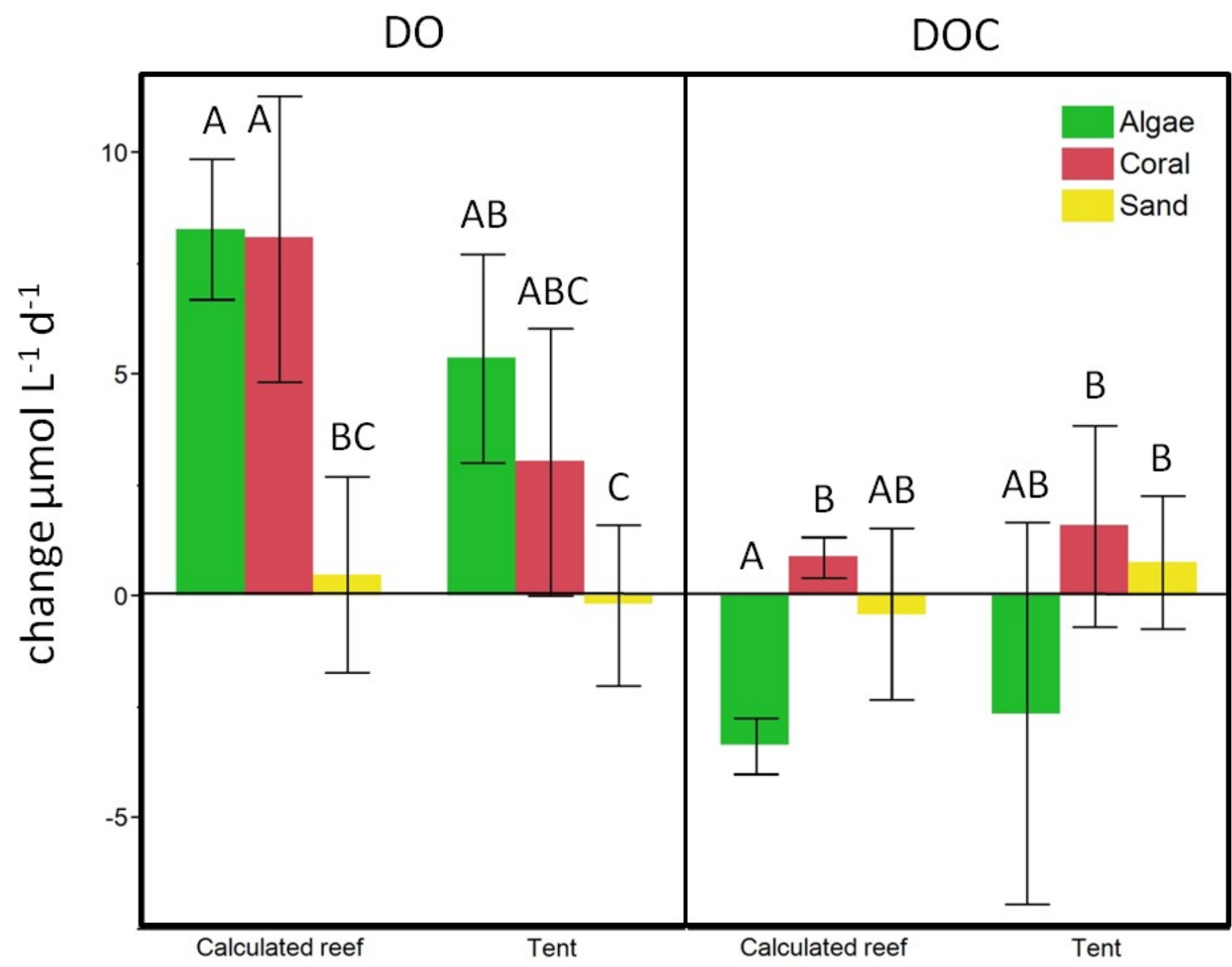

